\title{
Sobre la desestructuración y reconstitución del sindicalismo en Jujuy, Argentina, durante la Revolución Libertadora (1955-1958)
}

\author{
Fernando Aníbal Castillo*
}

Resumen: Con la deposición del gobierno de Perón, en septiembre de 1955, y la consecuente instauración del régimen denominado "Revolución Libertadora", se asistió en Argentina a un proceso de eliminación sistemática de los elementos vinculados al peronismo. Estos procedimientos alcanzaron también al movimiento obrero:se llevó a cabo la depuración de dirigentes peronistas de sus filas, se intervinieron los gremios, y en definitiva, se generaron consecuencias desfavorables para el conjunto de los trabajadores. La militancia peronista respondió al ataque perpetrado por el gobierno; a través de diversas tácticas dio lugar a la llamada "resistencia peronista". Estos términosse diseminaron por todo el país, incluyendo a la provincia de Jujuy, ubicada en el noroeste. En este artículo se determinan las características del proceso de desestructuración y reconstitución de los gremios de la provincia de Jujuy durante la Revolución Libertadora.

Palabras clave: Revolución Libertadora; Resistencia Peronista; Sindicalismo.

\begin{abstract}
Once Peronist Government was overthrown (September 1955), the regime so-called "Revolución Libertadora" was instituted. This administration carried out a systematic elimination process of all element linked to Peronism. These procedures also reached labour movement: Peronist leaders were purged, unions were taken over, and workers as a whole were severely damaged. Peronist militants reacted to the governing attack; by the means of several tactics so-called "Peronist Resistance" was carried out. These terms were spread throughout the entire country, including Jujuy (a northern Argentina province). In this paper the features of the process of disorganization and reconstitution of unions in Jujuy for the period of Revolución Libertadora are established.
\end{abstract}

Keywords: Peronist Resistance, Revolución Libertadora, Unionism.

* Doctor en Humanidades (Área historia). Docente de la Universidad Nacional de Jujuy. Becario postdoctoral del Consejo Nacional de Investigaciones Científicas y Técnicas (CONICET) con lugar de trabajo en la Unidad de Investigación en Historia Regional (UNIHR-ISHIR-CONICET).Email: ferredbo@yahoo.com.ar. 


\section{Introducción}

Luego de una década de gobierno, el peronismo fue depuesto mediante un golpe de Estado. Iniciado el 16 de septiembre de 1955 por sectores antiperonistas civiles y militares, dio lugar al régimen denominado "Revolución Libertadora". La nueva gestión inició un proceso orientado a redefinir las políticas públicas bajo principios antiperonistas, erradicando a todo elemento vinculado al peronismo. Los fundamentos de tal procedimiento suponían la restitución de la libertad y la democracia (conculcadas, a los ojos del antiperonismo, por el gobierno de Perón), el fin de la "politización" de ámbitos como la educación y el espacio público, y la imposición de límites a la lógica estatal.

El proceso de desperonización se diseminó por el territorio nacional, incluyendo a la provincia de Jujuy. Ubicada en el noroeste de Argentina (en la frontera, junto a Bolivia y Chile), esta jurisdicción también fue sometida (no sin el apoyo de vastos sectores sociales y políticos) al mando "revolucionario". Durante el período correspondiente a esta administración (1955-1958), se sucedieron una Intervención Militar y tres Intervenciones Federales, gestiones que procuraron sentar las condiciones para la constitución de un modelo sociopolítico sin contaminaciones peronistas.

Como en el resto del país, en Jujuy las autoridades de la tutela "libertadora" implementaron políticas específicas en esferas como el mundo del trabajo. Similarmente, aunque con trayectorias locales particulares, el gobierno provincial avanzó contra un ámbito de manifiesta tendencia favorable a Perón. En ese sentido, relevó a dirigentes sindicales peronistas, intervino gremios -liderados por seguidores del ex - presidente-, vació a la propia Confederación General del Trabajo (CGT) -asimismo en manos peronistas- y también favoreció a dirigentes antiperonistas. La política oficial, coadyuvante con las operaciones anti-obreristas de diversas empresas, generó un escenario que atentó contra el conjunto de los asalariados, incluyendo la caída de los salarios y el empeoramiento de las condiciones de trabajo y de existencia.

No obstante, del otro lado, la militancia peronista optó por no permanecer impávida ante la embestida del régimen castrense. Bajo múltiples mecanismos y diversas formas de organización, emergió la resistencia peronista, cuyanaturaleza implicaba el ejercicio de la disidencia. ${ }^{1}$ Jujuy también advino como teatro de

1 De acuerdo con Daniel James, la "resistencia” remite en general a la oposición ejercida desde el peronismo luego de su derrocamiento, en septiembre de 1955. Constituida en función del rechazo a la Revolución Libertadora, la resistencia representaba la capacidad del peronismo de enfrentar su proscripción y represión. JAMES, Daniel. “The Peronist Left, 1955-1975”. Journal of Latin American Studies, vol. 8, n², p. 273-296 (1976). Coincidiendo con James, Melon Pirro apunta que el móvil no era sino "la necesidad de 'hacer algo' frente a la omnipotencia ‘gorila’ y sus símbolos; y que por norma no se reconozca más ideología inspiradora que el sentimiento peronista ofendido y la necesidad de expresar la lealtad incondicional al jefe exiliado". MELON PIRRO, Julio. El peronismo después del peronismo: resistencia, sindicalismo y política luego del 55. Buenos Aires: Siglo Veintiuno, 2009, p. 56. Dentro de la vasta bibliografía al respecto, consultar, además de las ya citadas, las siguientes publicaciones: SALAS, Ernesto. La resistencia peronista, la toma del frigorífico Lisandro de la Torre (Tomo 1). Buenos Aires: Centro Editor de América Latina, 1990; RAIMUNDO, Marcelo. "Acerca de los orígenes del peronismo revolucionario". In: CAMARERO, Hernán; POZZI, Pablo; SCHNEIDER, Alejandro. De la Revolución Libertadora al menemismo. Buenos Aires: Imago Mundi 2003, pp. 75-105; RAIMUNDO, Marcelo. "La política armada en el peronismo: 1955-1966". Cuadernos del CISH, n 4, p. 210-231 (1998); JAMES, Daniel (Dir.). "Sindicatos, burócratas y movilización”. In: Violencia, proscripción y autoritarismo: 1955-1976. Buenos Aires: Sudamericana, 2007, pp. 117-167; BOZZA, Juan. “El peronismo revolucionario. Itinerario y vertientes de la radicalización, 1959-1969”. Sociohistórica, n 9-10, p. 135-169 (2001); MELON PIRRO, Julio. "La resistencia peronista. Alcances y significados". Anuario del IEHS, $n^{\circ} 8$, p. 215-246 (1993). 
operaciones de las incursiones de la resistencia; desde el sabotaje de los servicios públicos hasta la planificación de acciones armadas, el peronismo local dejó en claro que el horizonte estaba puesto en el retorno al período previo a septiembre de 1955. En este contexto marcado por la represión estatal y la resistencia, se desenvolvieron los vaivenes de los trabajadores y del sindicalismo, con sus propias condiciones e itinerarios.

El presente artículo determina las características del proceso de desestructuración y reconstitución de los gremios de la provincia de Jujuy durante la Revolución Libertadora. En un sentido más amplio, sin dejar de atender a las particularidades regionales, se apunta a contribuir a la historia del peronismo y el sindicalismo en Argentina. El artículo se desarrolla a partir de la consulta de diversos fuentes documentales de los siguientes repositorios: Archivo Histórico de la Provincia de Jujuy, Archivo de Tribunales de Jujuy, el Archivo Histórico de la Justicia Federal, Archivo Histórico de la Legislatura de la Provincia de Jujuy, Archivo Intermedio del Archivo General de la Nacióny Hemeroteca de la Biblioteca Popular de Jujuy. ${ }^{2}$ Finalmente, el artículo se encuentra guiado por las siguientes premisas: primero, la desestructuración de las organizaciones obreras peronistas en esta provincia durante la Revolución Libertadora fue producto de la confluencia de la represión estatal, la promoción del sindicalismo antiperonista y la temprana actuación de dirigentes sindicales en otras áreas de la resistencia. En segundo lugar, la reemergencia y recuperación del sindicalismo peronista jujeño radicó en la articulación, en el contexto de normalización gremial, de una militancia activa permanente y el reflujo de dirigentes hacia la lucha sindical.

\section{Sobre la provincia de Jujuy: configuraciones y modulaciones en el ejercicio del poder}

Las características sociales, económicas y políticas más importantes de esta provincia, durantela primera mitad del siglo pasado, comportaronla preponderancia de los ingenios azucareros en el condicionamiento de los procesos que se desarrollaban en esta jurisdicción. ${ }^{3}$ Como agentes productivos con gravitación en

2 En el conjunto de instituciones señaladas se resguarda una importante cantidad y diversa de fuentes documentales, vinculadas no solo a la temática estudiada en el presente artículo, sino en general al período de la Revolución Libertadora (1955-1958). En el Archivo Histórico de la Provincia de Jujuy, se localiza un extenso número de expedientes, en los cuales predominan aquellos aspectos vinculados a las políticas del gobierno militar y en menor medida, información sobre la resistencia peronista. Cabe acotar que en el mismo repositorio se dispone de datos sobre variados procesos sociohistóricos, como la dinámica de los partidos políticos. En el Archivo de la Justicia Federal de Jujuy se aloja una pequeña cantidad de expedientes, aunque algunos de gran volumen. Uno de estos, de aproximadamente medio metro lineal, consta de centenares de fojas en las cuales se da cuenta del accionar de la justicia federal y las fuerzas armadas y semi-militarizadas, como la policía y la gendarmería, y asimismo consta de una gran cantidad de información acerca de la resistencia peronista. En el Archivo Histórico de la Legislatura de la Provincia de Jujuy se encuentran fuentes primordialmente sobre las dos siguientes temáticas: los partidos políticos y las comisiones investigadoras, que sometieron a indagación parajudicial a los funcionarios peronistas. El corpus documental de este archivo contiene en general escasas fuentes sobre los años posteriores a 1955, aunque hace posible la reconstrucción del devenir de los procesos políticos en los años del golpe. En el Archivo de Tribunales de la Provincia de Jujuy se halla información sobre diversos procesos represivos y judiciales seguidos contra actores vinculados al gobierno peronista luego de su derrocamiento. En la Hemeroteca de la Biblioteca Popular de Jujuy se hallan los diarios publicados en esta provincia entre los años 1955 y 1958. Las series editadas de los diarios Crónica, Jujuy, Libertad y Pregón constituyen algunas de las ediciones consultadas en el marco esta investigación.

3 KINDGARD, Adriana. Alianzas y enfrentamientos en los orígenes del peronismo jujeño. San Salvador de Jujuy: Unidad de Investigación en Historia Regional, FHYCS, UNJU, 2001. 
la estructura económica, ejercieron continuamente presiones sobre los gobiernos provinciales, estableciendo con libertad sus mecanismos de coacción contra sus trabajadores y participando asimismo con amplio margen en la definición de las políticas públicas. ${ }^{4}$ La explotación y las pésimas condiciones en cuanto vivienda y salubridad $^{5}$ a las que eran sometidos los asalariados de las empresas azucareras generaron el rechazo de vastos sectores políticos y favorecieron a la larga que la constitución de las identidades sociales y políticas en la provincia se estructuraran en torno a la fidelidad u oposición a estas firmas y sus aliados.

El escenario plenamente favorable para los ingenios cesó a partir de 1943, en cuanto asomó un régimen militar orientado bajo la consigna de intervenir en las relaciones entre la patronal y la fuerza de trabajo. Siguiendo esta línea, se evidenció rápida y categóricamente que el nuevo gobierno estaba dispuesto a prestar atenciones a los asalariados. ${ }^{6}$ En el contexto de la provincia de Jujuy, las prescripciones sugeridas por la administración castrense fueron seguidas, y la preeminencia conferida a los obreros se hicieron ostensibles en la esfera de influencia de los establecimientos azucareros. Con la sanción e implementación de leyes (como aquella que ponía límites a las prácticas de reclutamiento coactivo de peones), los ingenios verían damnificados sus intereses. Así se hizo ostensible además la posición que había asumido el Estado provincial, postura que se haría extensiva durante el gobierno peronista, consagrado en las urnas a principios de 1946 (aunque de conformación paulatina a lo largo de los tres años precedentes). ${ }^{7}$

En Jujuy el movimiento peronista se construyó a partir de su diferenciación con el conservadurismo y la oligarquía azucarera. Dado el rechazo de los simpatizantes de Perón hacia estos actores, el naciente colectivo peronista adquirió un carácter inapelablemente antioligárquico. ${ }^{8}$ Más allá de ganar la abominación de los sectores mencionados, el gobierno peronista obtuvo además la aversión de otros sectores sociales y políticos, como el partido Unión Cívica Radical; este último, aunque compartía el ímpetu peronista por combatir los privilegios de los azucareros, impugnaba el uso de la propaganda y la politización de diversas esferas, como la escuela, además de manifestar suma preocupación por la organización del movimiento obrero bajo la égida estatal. Estos mecanismos sugirieron a sus opositores motejar al gobierno como fascista. ${ }^{9}$

No obstante, la oposición del sector antiperonista, el movimiento liderado por Perón se impuso a lo largo de una década de manera inclemente en las lides electorales. Solo un movimiento armado, en septiembre de 1955, logró destituir

4 LAGOS, Marcelo. "Conformación del mercado laboral en la etapa de despegue de los ingenios azucareros jujeños (1880-1920)". In: CAMPI, Daniel (Comp.). Estudios sobre la historia de la industria azucarera argentina - II. San Salvador de Jujuy: Unidad de Investigación en Historia Regional (UNJU), Ediciones del Gabinete Secretaría de Postgrado (UNT), 1992, p. 51-90.

5 TERUEL, Ana; FLEITAS, María Silvia. "Historiando las revelaciones de Bialet Massé en torno a los trabajadores y conflictos sociales en los ingenios de Jujuy". In: LAGOS, Marcelo; FLEITAS, María Silvia; BOVI, María Teresa (Comps.). A cien años del informe Bialet Massé. El trabajo en la Argentina del siglo XX y albores del XXI (Tomo 1). San Salvador de Jujuy, Ediunju-UNHIR, 2004, p. 135-155.

6 TORRE, Juan Carlos (Dir.). “Introducción a los años peronistas”. In: Los años peronistas (1943-1955). Buenos Aires: Sudamericana, 2002, p. 11-77.

7 FLEITAS, María Silvia; KINDGARD, Adriana. "Entre la legalidad y la proscripción. Políticas públicas y lucha obrera en Jujuy”. In: TERUEL, Ana; LAGOS, Marcelo (Dirs.). Jujuy en la historia. De la colonia al siglo XX. San Salvador de Jujuy: Ediunju, 2006, p. 185-239.

8 KINDGARD, Adriana. "Ruptura partidaria, continuidad política. Los "tempranos" orígenes del peronismo jujeño”. In: En MACOR, Darío; TCACH, César (Eds.), La invención del peronismo en el interior del país. Santa Fe: Universidad Nacional del Litoral, 2003, p. 163-212.

9 CASTILLO, Fernando. "Antiperonismo y resistencia en Jujuy durante la Revolución Libertadora". (Tesis de doctorado, Universidad Nacional de Tucumán). 
al peronismo. Las consecuencias de la instauración de la Revolución Libertadora supusieron transformaciones considerables en la estructura de poder provincial.

Consumada la destitución del peronismo, las fuerzas sublevadas se apropiaron del aparato del Estado. La presidencia de la Nación fue conferida en primera instancia al general Eduardo Lonardi, representante de la facción nacionalista del Ejército; en cuanto a Jujuy, la autoridad le fue conferida a la Intervención Militar, cuyo titular era el teniente coronel Jorge Alvarado. El principal lema de la Revolución Libertadora pregonaba la restitución del imperio del derecho y la pacificación de la nación. ${ }^{10}$ Sin dudas, el discurso del gobierno castrenseprovincial favorecía a simple vista la ratificación del programa lonardista, fundado en la conciliación; al respecto, el jefe del Ejecutivo declaró: "Haré todo lo posible, con la energía necesaria, para que Jujuy ( ) se encamine por el camino de paz que le marcan las nuevas autoridades, en procura de la pacificación del país y el reencuentro de sus hijos"." Lejos de la paz y la libertad prometida, las políticas de la Intervención Militar dieron cuenta rápidamente de sus objetivos: a partir de la emergencia de este mandato se inició la represión y la persecución del peronismo, en las que el Ejército tomó activa participación en la encarcelación de sus militantes. ${ }^{12}$ Asimismo, también se dio curso a la depuración de la administración pública; iniciando un proceso que semanas más tarde se exacerbaría, se llevaron a cabo las primeras cesantías.

Más allá de las prácticas represivas señaladas, los antiperonistas radicalizados regañaron a Lonardi por inacción en contra del peronismo; esto (sumado ciertamente a otras críticas por parte de los partidos políticos) desacreditó rápidamente la imagen de Lonardi frente al antiperonismo. La decisión de no intervenir los sindicatos y de respetar los privilegios normativos que gozaba la clase obrera no fueron bien recibidos por el sector liberal del antiperonismo. Los dirigentes sindicales postergados desde hacía años por el peronismo demandaron la desperonización del movimiento obrero. Rodríguez Lamas nota, no obstante, que la beligerancia por el control sobre los sindicatos no constituía el problema de fondo; antes bien, señala, "las raíces más profundas del enfrentamiento giraron en torno al mantenimiento o supresión de la modalidad de integración de los sindicatos al Estado que se había desarrollado durante la década peronista". ${ }^{13}$

La conciliación no pudo concretarse en definitiva por falta de consenso entre las líneas antiperonistas. Cuestionado por su posicionamiento indulgente con los derrocados, el primer presidente provisional fue desalojado. En su lugar, asumió la primera magistratura el oficial del Ejército Pedro Eugenio Aramburu, más proclive a la postura liberal y a los partidos políticos. El relevo de la consigna "conciliación" por "democracia”, orientación auspiciada por la tradición liberal-democrática y subsumida bajo la consigna de "Mayo-Caseros", puso de manifiesto la orientación que le sería conferida a la Revolución Libertadora. ${ }^{14}$

Con respecto al embate contra el peronismo, las prácticas represivas puestas

10 SPINELLI, María Estela. Los vencedores vencidos. El antiperonismo y la "Revolución Libertadora". Buenos Aires: Biblos, 2005.

11 Hemeroteca de la Biblioteca Popular de Jujuy (en adelante HBPJ). Crónica. 24 de septiembre de 1955.

12 Archivo de Tribunales de Jujuy (en adelante ATJ). Conservación Civil 1952-1957. Expediente $N^{\circ}$ 239/1955 [Expurgo: 1955. Orden: 1].

13 RODRÍGUEZ LAMAS, Daniel. La Revolución Libertadora. Buenos Aires: Centro Editor de América Latina, 1985 , p. 109.

14 SPINELLI, María Estela. “La 'Revolución Libertadora'. Proyección política. Un análisis sobre su lugar en la historiografía”. In: SPINELLI, María Estela; SERVETTO, Alicia; FERRARI, Marcela; CLOSA, Gabriela (Comps.), La conformación de las identidades políticas en la Argentina del siglo XX. Córdoba: Universidad Nacional de Córdoba: Universidad Nacional del Centro de la Provincia de Buenos Aires: Universidad Nacional de Mar del Plata, 2000, p. 189-220. 
en operación dejaron traslucir que el binomio gubernamental Aramburu-Rojas abandonaría toda ambigüedad. ${ }^{15}$ Los militantes peronistas fueron apresados e interrogados en función de las prácticas inquisitivas de las comisiones investigadoras, formadas "para atender a las múltiples denuncias de corrupción y abuso de poder que pesaban sobre el gobierno derrocado". ${ }^{16}$ Además, se proscribió al Partido Peronista, se intervino la CGT, la persecución de la militancia peronista adquirió naturaleza sistemática y se sancionó "la penalización de la apelación a sus símbolos. ${ }^{17}$

En Jujuy, de manera casi coincidente con las tendencias nacionales, a la primera tutela "libertadora" le siguió la Intervención Federal "cuyo mandato le fue conferido por el Gobierno Nacional al contralmirante Gastón Clement en octubre de 1955". Esta gestión fue sumamente coherente con el planteo del gobierno de Aramburu y Rojas. Las tendencias fuertemente represivas y antiperonistas en Jujuy fueron prolongadas, ampliadas y organizadas por la segunda Intervención. Las políticas de desperonización que se habían desarrollado de manera arbitraria semanas antes fueron investidas ahora de carácter sistemático. La urgencia, que había sido el principio que guió a la Intervención Militar, fue sustituida por un proceso a mediano plazo que se extendió durante los siguientes meses a lo largo de un paulatino desmontaje de los "resabios del totalitarismo". Se profundizaron así todos los mecanismos de expulsión de los peronistas y sus símbolos de las instituciones y de toda la esfera pública, se incrementaron los operativos de represión y asimismo se instauraron procedimientos de indagación que recayeron sobre el "régimen depuesto" y sus acólitos.

La respuesta que los peronistas dieron ante tal embestida, como ya se adelantó, no fue pasiva: los proscriptos dieron lugar a prácticas fundadas en la disidencia contra la Libertadora. ${ }^{18} \mathrm{Si}$ bien desde los primeros días luego de la expulsión del peronismo sus militantes habían puesto en operación acciones como hacer circular rumores o panfletos, ${ }^{19}$ estos actores irían alcanzando cada vez mayor organización, que se exteriorizaría en acciones de sabotaje, panfleteo y en la preparación (el primero en Jujuy) de un plan a realizar en esta provincia en caso de un levantamiento armado. ${ }^{20}$ Una de las características de la resistencia peronista en Jujuy estuvo dada en que durante el primer año de la "Libertadora" los militantes le brindaron preponderancia a los comandos (unidades orientadas mayormente a la ejecución de sabotajes, que en esta provincia privilegiaron la

15 MELON PIRRO, Julio. "La corrección de la historia: proyectos institucionales y pedagogía democrática en el primer post-peronismo”. In: SPINELLI, María Estela; SERVETTO, Alicia; FERRARI, Marcela; CLOSA, Gabriela (Comps.), La conformación de las identidades políticas en la Argentina del siglo XX. Córdoba: Universidad Nacional de Córdoba: Universidad Nacional del Centro de la Provincia de Buenos Aires: Universidad Nacional de Mar del Plata, 2000, pp. 221-248.

16 SPINELLI. “La 'Revolución Libertadora’. Proyección”, p. 191.

17 SPINELLI, María Estela. "El debate sobre el orden político durante los primeros gobiernos antiperonistas, 1955-1958”. Anuario del IEHS, n 16, p. 13-37 (2001), p. 19

18 En el contexto del ejercicio de las luchas sindicales, cabe señalar que la oposición provino también de actores de filiación no peronista. Tal fue el caso de sectores que provenían del socialismo y el trotskismo, y que durante la primera mitad de la década de 1950 confluyeron en el Partido Socialista de la Revolución Nacional. Aunque a lo largo de ese período le brindaron colaboración a la gestión de Perón, con la llegada de la "Libertadora", estos actores militaron independientemente de la resistencia peronista, en particular, procurando organizar a los trabajadores estacionales de los ingenios azucareros. No obstante, su participación en tal esfera fue rápidamente reprimida por el gobierno militar, a principios de 1956. AHJ. Expediente $\mathrm{N}^{\circ}$ 595-M-1956. Luego de ser sometidos a procesos judiciales, algunos se abocaron al trabajo periodístico y otros, a la representación de asalariados jujeños en demandas contra empresas, en casos como despidos injustificados.

19 Archivo Histórico de la Justicia Federal (en adelante AJF). Expediente N 928-1956.

20 HBPJ. Pregón. 24 de enero de 1956. 
preparación de acciones armadas), en detrimento de la lucha sindical y partidaria.

El gobierno puso en práctica fuertes operativos policiales, en los que se arrestaban a decenas de personas que además del encarcelamiento, eran sometidos a procedimientos judiciales. La represión al peronismo alcanzaría en adelante no sólo a aquellos que participaron del "régimen depuesto", sino también a aquellos que pugnaban por reinstalarlo. En octubre de1956, en función del concurso y confluencia sobre los peronistas del conjunto de las instituciones judiciales, policiales y militares, los comandos fueron desarticulados casi por completo, y la resistencia peronista pasaría de los comandos a las acciones partidarias y a las prácticas sindicales.

\section{Acerca de la represión del movimiento obrero en Jujuy}

Luego de la enérgica embestida gubernamental sobre los comandos, durante el segundo semestre de 1956, la resistencia peronista fue girando hacia otras líneas de acción. Dada la poca factibilidad de un complot para deponer a los "libertadores", los peronistas comenzaron a ensayar con mayor preponderancia la oposición sindical. Sin dudas esta opción ya se había encontrado en operación desde los albores de la Revolución Libertadora, pero ahora, los actores de la resistencia más radicalizados orientaron sus expectativas en esa dirección, confiriéndole verdadera fuerza en las disputas con el antiperonismo. Este viraje en el mundo gremial jujeño se contextualizó en las prácticas del sindicalismo peronista, que paulatinamente había ido recuperando el protagonismo en la escena política nacional. Por otro lado, cabe acotar, los peronistas también apostaron por la militancia a través de los partidos políticos. Debe tenerse en cuenta que en la opción entre la trayectoria sindicalista y la partidaria no hubo necesariamente una disyuntiva. Si bien a lo largo de la Revolución Libertadora los peronistas escogieron entre la lucha sindical, las acciones de los comandos y la construcción de una alternativa partidaria, Ilegada la instancia decisiva de definir el próximo gobierno por la vía electoral, los militantes de las distintas ramas del peronismo confluyeron en la discusión sobre el camino que, en la coyuntura, debería seguir el peronismo jujeño. ${ }^{21}$

Lejos de perder su identidad peronista, el movimiento obrero la consolidó, aunque emergió como un actor que manifestaba autonomía. ${ }^{22}$ En principio, James sugiere que el peronismo asistió luego del golpe de septiembre de 1955 a un estado de estupefacción e incredulidad. Esta condición daría lugar rápidamente a una serie de manifestaciones de naturaleza espontánea "en los distritos obreros de las principales ciudades". ${ }^{23}$ El autor señala que a lo largo del mes de octubre de 1955 se sucedieron huelgas que expresaban la disconformidad de los trabajadores peronistas, fundamentalmente contra los ataques de los comandos civiles y el gran número de detenciones de sus correligionarios. James destaca que estas huelgas no fueron dispuestas por los dirigentes sindicales, sino ejecutada sin mediaciones gremiales por los militantes de base: "la índole de esa oposición de

21 CASTILLO. "Antiperonismo y resistencia".

22 CAVAROZZI, Marcelo. "Peronismo, sindicatos y política en Argentina (1943-1981)". In: GONZÁLEZ CASANOVA, Pablo (Ed.). Historia del movimiento obrero en América Latina. México D.F.: Siglo Veintiuno, Instituto de Investigaciones Sociales de la UNAM, 1984-1985, p. 200-250.

23 JAMES, Daniel. Resistencia e Integración. El peronismo y laclasetrabajadora argentina, 1946-1976). Buenos Aires: Siglo XXI, 2006, p. 77. 
las bases ( ) [fue] fundamentalmente espontánea, instintiva, confusa y acéfala". ${ }^{24}$ Por otro lado, el movimiento obrero, sugiere Torre operó luego de la deposición del peronismo como el canal a través del cual circularon las demandas de los trabajadores, reemplazando al partido. ${ }^{25}$

El sindicalismo en esta provincia, no obstante, siguió una trayectoria diversa a la de otros distritos. Si bien en definitiva los sindicatos jujeños terminaron desembocando en un resultado coincidente con otras jurisdicciones (la recuperación de numerosos gremios y la reconstitución de la CGT), los pasos seguidos tuvieron su especificidad. Inmediatamente después del golpe del 16 de septiembre, el movimiento obrero organizado de Jujuy dio muestras de precaución ante el escenario político-sindical. Durante los días siguientes al levantamiento militar, los dirigentes de la CGT instaron mediante comunicados a los afiliados a no abandonar sus obligaciones laborales y a servir "invariablemente al orden". ${ }^{26}$ Finalmente, les encomendaron que no obedecieran y se mantuvieran fuera de contacto con grupos contaminadores y perturbadores. La actitud asumida sugería que la CGT provincial parecía estar más dispuesta a claudicar que a defender a Perón y su gobierno.

Luego de la instalación de Lonardi en la presidencia, la postura oficial sobre el sindicalismo no denotó todavía animosidad. La conciliación favorecida por los nacionalistas distaba de la posición del grueso del antiperonismo, expresada en la agresión a los gremios mediante los comandos civiles. La invitación lonardista fue bien recibida en Jujuy (aunque, como en otras partes, la sede sindical fue objeto de ataques). ${ }^{27}$ Los dirigentes gremiales "de la misma forma que los líderes partidarios" se presentaron y reconocieron a la autoridad investida en la Intervención Militar. ${ }^{28}$ Durante los días siguientes a la asunción del gobierno "libertador" en Jujuy, la nueva gestión recibió a delegaciones del Sindicato de Obreros y Empleados del Azúcar de La Esperanza ${ }^{29}$, del Sindicato de Taxis y de una cooperativa ferroviaria de San Salvador de Jujuy (ciudad capital de la provincia). ${ }^{30}$ En todos estos casos le plantearon diferentes problemas relacionados con las condiciones laborales que las autoridades se comprometieron a resolver. La Intervención Militar también recibió al delegado general de la CGT en Jujuy, Raúl Valenzuela -ex-diputado provincial por el Partido Peronista desde principios de 1955 hasta la "Revolución"-, junto a otros dirigentes de la central obrera local; los representantes cegetistas recibieron la permisión de realizar una reunión en la que se pondría a consideración el programa del presidente Lonardi. ${ }^{31}$ Asimismo, a principios de octubre visitaron al titular del ejecutivo provincial los líderes del Sindicato de Trabajadores del Ingenio Ledesma, acompañados por el secretario general de la CGT en Jujuy. Estos últimos manifestaron al interventor "el propósito de todo el sector obrero ( ), de continuar, como hasta aquí, cumpliendo con sus tareas en forma ordenada y pacífica". ${ }^{32}$ El secretario de la CGT avaló la propuesta de los obreros del Ingenio, y expresó asimismo que "en el ambiente azucarero

24 JAMES. Resistencia e Integración, p. 79.

25 TORRE, Juan Carlos. “La tasa de sindicalización en la Argentina”. Desarrollo económico, vol. 12, n 48, p. 903-913.

26 HBPJ. Crónica. 20 de septiembre de 1955.

27 ATJ. Conservación Civil 1952-1957. Expediente N²39/1955 [Expurgo: 1955. Orden: 1].

28 Archivo Histórico de la Legislatura de la Provincia de Jujuy (en adelante AHL). Caja: Antecedentes generales (I. F.) $N^{\circ}$ 1. Carpeta: C. I. N ${ }^{\circ}$.

29 HBPJ. Jujuy. 27 de septiembre de 1955.

30 HBPJ. Jujuy. 30 de septiembre de 1955.

31 HBPJ. Crónica. 1 de octubre de 1955.

32 HBPJ. Crónica. 4 de octubre de 1955. 
de Ledesma reina la tranquilidad que es precursora del trabajo destinado a la producción intensiva". ${ }^{33}$ El trato instituido supuso asimismo el reconocimiento de la Intervención como interlocutor legítimo entre las demandas obreras y el Estado. El establecimiento y sostenimiento de estos canales entre los gremios y la central de los trabajadores jujeños con el gobierno supuso que ambos actores asumieron una posición no necesariamente confrontacionista con respecto al otro, siguiendo la línea pacificadora del régimen lonardista.

Sin embargo, el panorama sindical luego del advenimiento de la Intervención Federal de Clement, menos proclive al entendimiento con los gremios (preanunciando la política aramburista), se complejizó por dos cuestiones, en definitiva, enlazadas. Primero, por la emergencia del sindicalismo sin raigambre peronista (estimulada por el antiperonismo poco propenso a la conciliación, resurgido con el advenimiento de la línea liberal), denominado "sindicalismo libre". Segundo, por el tratamiento represivo que recibió el gremialismo por parte de la Intervención, inaugurando una postura alejada ya de la pacificación. A través de ambos procesos, de manera connivente, se logró reducir categóricamente el control que los peronistas ejercían en los gremios y por ende en la CGT de Jujuy. La política del gobierno provincial se enmarcaba dentro de las propensiones del gobierno central, cuya prerrogativa suponía la liquidación del movimiento obrero peronista. ${ }^{34}$

Por otro lado, "luego de los cambios en la conducción nacional, a partir del desplazamiento de los sectores nacionalistas por el ala liberal del movimiento, muy dispuesta a suprimir al peronismo" la política del gobierno de facto con respecto a la CGT, el movimiento obrero y los trabajadores en general viraría hacia una posición más dura. Sin embargo, siguiendo también la dinámica nacional, el movimiento obrero de Jujuy procuró dar muestras de que la postura conciliatoria había concluido. Así, A mediados de noviembre de 1955, mediante la convocatoria de la CGT, se llevó a cabo una huelga en la provincia, la primera en tiempos "revolucionarios". El gobierno provincial, al respecto, manifestó lo siguiente:

La Intervención Federal comunica a la población que la jornada laboral fue normal en toda la provincia, con la sola excepción de un paro parcial en el ( ) [Ingenio] Ledesma, producido por un diferendo en la parte patronal y la parte obrera, solucionado satisfactoriamente en horas de la tarde. ${ }^{35}$

El paro azucarero puso de manifiesto que los trabajadores de los ingenios no estaban dispuestos a ser sometidos sin oponer resistencia y además que representaban uno de los sectores más combativos del movimiento obrero, sin dudas, de filiación peronista. Las autoridades "libertadoras" tampoco estaban dispuestas a ceder, en este caso frente a los improperios de los agitadores azucareros. La huelga llevó al gobierno y a los ingenios a la remoción de las autoridades del conjunto de los gremios azucareros.

En cierto sentido, la huelga azucarera permite vislumbrar ciertas coincidencias con el planteo señalado por James. El pasaje del lonardismo al régimen de Aramburu conllevó un proceso de transformación en el repertorio de acciones de protesta y asimismo del ámbito de ejercicio de la misma. Durante el primer

33 HBPJ. Crónica. 4 de octubre de 1955.

34 CAVAROZZI. "Peronismo, sindicatos".

35 HBPJ. Jujuy. 17 de noviembre de 1955. 
gobierno provisional, la oposición peronista se ejecutó contra los arrestos y la ocupación de los gremios por los comandos antiperonistas. Advenida la regencia de Aramburu, la resistencia se trasladó a la fábrica, fundamentalmente contra la política económica de la Revolución Libertadora. ${ }^{36}$ Cabe acotar al respecto que la política de la Revolución Libertadora con respecto a la clase trabajadora se asentó en tres líneas que implicaban los siguientes elementos: la proscripción de dirigentes sindicales peronistas, la represión de las bases sindicales, y el intento de racionalizar el trabajo asalariado. ${ }^{37}$

La represalia oficial y empresarial a la huelga azucarera impactó de sobremanera en el movimiento obrero jujeño, interrumpiendo en gran medida las acciones de protesta. Los procedimientos represivos que cayeron sobre los militantes sindicales de la provincia empujaron a algunos de ellos a participar de los comandos, como un espacio más propicio para el ejercicio de la resistencia.

En adelante, los gremios azucareros fueron controlados por empleados "patronalistas", 38 impuestos a través de intervenciones gubernamentales con la venia de los ingenios. El conjunto de las organizaciones obreras de los trabajadores del rubro fue alcanzado por estas prácticas. El Sindicato de Obreros y Empleados de Calilegua (Afiliado a la Asociación de Trabajadores de Azúcar Jujuy y a la CGT), ${ }^{39}$ la Asociación de Trabajadores del Azúcar (Sección Ledesma) ${ }^{40}$ y el Sindicato de Obreros y Empleados del Ingenio Ledesma ${ }^{41}$ fueron todos sometidos a comisiones interventoras que terminaron designando autoridades afines a los ingenios. Este esquema también fue desarrollado en otros casos, en los que los dueños de las empresas impusieron a los dirigentes de los gremios o de las comisiones internas. ${ }^{42}$

Este procedimiento fue sólo el preludio de una postura más agresiva con los asalariados organizados. La central de los trabajadores fue intervenida en noviembre de 1955 y asimismo todos los centros regionales sometidos a su jurisdicción. ${ }^{43}$ Esta medida, que implicaba asimismo la caducidad de los mandatos de los dirigentes sindicales, se fundó en el propósito de reestructurar la central obrera. De acuerdo a un comunicado emitido por la Intervención Federal, esta disposición se basó en las premisas del gobierno central:

Siguiendo el programa de restablecer la libertad y la democracia [el Superior Gobierno Provisional] ha emancipado ayer a los trabajadores del país de la dictadura a que los tenían sometidos los dirigentes de la Confederación General del Trabajo, que solo fueron hasta ahora obsecuentes servidores de un régimen nefasto para la patria. ${ }^{44}$

En la provincia de Jujuy, ante la cesación de las autoridades de la CGT, la Intervención dispuso que las fuerzas de seguridad "vigilasen" los locales de la central obrera (esto es, se apropiasen). La administración "libertadora" adujo que las sedes gremiales, en cuanto bienes de los trabajadores, serían devueltos

\footnotetext{
36 JAMES. Resistencia e Integración, p. 82.

37 JAMES, Daniel. "Rationalisation and Working Class Response: The Context and Limits of Factory Floor Activity in Argentina". Journal of Latin American Studies, vol. 13, n² 2, p. 375-402 (1981).

38 HBPJ. Pregón. 16 de marzo de 1957.

39 Archivo Histórico de la Provincia de Jujuy (en adelante AHJ). Expediente № 1543-S-1956.

40 AHJ. Expediente $N^{\circ} 410-A-1956$.

41 AHJ. Expediente N ${ }^{\circ}$ 995-S-1957.

42 HBPJ. Pregón. 24 de febrero de 1957.

43 HBPJ. Crónica. 17 de noviembre de 1955.

44 HBPJ. Jujuy. 18 de noviembre de 1955.
} 
“a quienes resultaren libremente elegidos por los sindicatos". ${ }^{45} \mathrm{En}$ tal contexto, se advirtió a los trabajadores:

Deben rechazar toda directiva de quienes ( ) [invoquen] su representación por cuanto carecen de ella, y cuyos propósitos no serán otros que el de pretender mantener sus privilegios y prebendas a expensas de los trabajadores, al mismo tiempo que seguir incitando a los sindicatos a participar en estos actos políticos en lugar de defender los intereses gremiales sanos y auténticos. ${ }^{46}$

El 5 de diciembre, de acuerdo a instrucciones expresadas por el Ministerio de Trabajo y Previsión, fue intervenida la Delegación Regional del Trabajo y Previsión en la provincia de Jujuy. El capitán Horacio Isidro Massanes fue designado interventor. Las autoridades que actuaban en la delegación local de la CGT dispusieron la intervención de varios sindicatos en los departamentos de Ledesma y San Pedro, entre otros, del Sindicato de Taximetristas de Ledesma, la Unión Obrera Argentina de San Pedro, Unión Obrera de la Construcción de San Pedro, Sindicato de Obreros Panaderos de San Pedro, Sindicato de Empleados de Comercio de San Pedro. ${ }^{47}$ Como las mismas autoridades de la Intervención Federal aseverarían en varias ocasiones, en ese proceso el gobierno militar pretendió separar la política de la esfera sindical, esto es, anular el peronismo, de la misma forma que intentaría realizarlo en otros ámbitos, como el educacional y el administrativo.

La promesa de entregar los gremios fue ratificada en mayo de 1956, en el contexto de la proclamación del plan nacional de normalización de los sindicatos. ${ }^{48}$ Sin embargo, los gremios jujeños nunca fueron restituidos a los trabajadores, dado que el proceso de normalización que se inició en esta provincia recién a principios de 1957 (aunque incluyó algunos referendos para la selección de delegados) no alcanzó a consumar la devolución de los mismos a los legítimos titulares.

Como se planteó anteriormente, la avanzada gubernamental contra los trabajadores fue coadyuvante a otro proceso. Así, se dio paso al proceso de emergencia de entidades gremiales nuevas, como el Sindicato Libre de Vendedores Ambulantes de Libertador General San Martín. En este caso se trató de una organización que surgió a la luz de la apertura hacia fuerzas gremiales no peronistas; este sindicato se presentó como "libre", lo que implicaba una posición política antiperonista, reforzada además por la disposición a ponerse incondicionalmente a las "gratas" órdenes de la Intervención Federal. 49

Desde los primeros días de octubre de 1955, el sindicalismo antiperonista dio lugar a un proceso orientado a la apropiación de los gremios provinciales. La Comisión administrativa de la Asociación de Trabajadores del Estado (ATE), Federación Palpalá, fue destituida; trabajadores antiperonistas desconocieron la representación del delegado provincial cegetista: "De acuerdo a nuestros estatutos el señor Raúl Ramón Valenzuela, Secretario General de la C.G.T. en la actualidad está ocupando una representación legal que no le corresponde." ${ }_{50}^{\circ} \mathrm{La}$ sede, en la ciudad de Palpalá, fue tomada y, luego de la destitución de hecho del cuerpo de representantes, se nombró a una comisión reorganizadora provisional.

\footnotetext{
45 HBPJ. Jujuy. 18 de noviembre de 1955.

46 HBPJ. Jujuy. 18 de noviembre de 1955.

47 HBPJ. Pregón. 24 de enero de 1956.

48 HBPJ. Libertad. 19 de mayo de 1956.

49 AHJ. Expediente $\mathrm{N}^{\circ} 435-\mathrm{S}-1955$.

50 AHJ. Expediente $\mathrm{N}^{\circ} 73-\mathrm{A}-1955$.
} 
En otro caso, una asamblea de maestros declaró caduca la Comisión Directiva de la Asociación de Educadores Provinciales (ADEP), que se encontraba en funciones desde 1954, y nombró una Comisión Provisional. ${ }^{11}$ En este caso no hubo en principio una toma forzosa del local gremial, aunque como ocurriera con la seccional Palpalá de ATE, se caducaron de hecho los mandatos de la dirigencia vigente. También fue apropiada por militantes antiperonistas la seccional Volcán de la Unión Ferroviaria, cuyas nuevas autoridades fueron ratificadas por la intervención al gremio ferroviario, que dispuso la Revolución Libertadora. ${ }^{52}$ Asimismo, los antiperonistas se hicieron con la Federación Gráfica ${ }^{53}$ y el gremio ferroviario de La Fraternidad. ${ }^{54}$ En este último caso, los peronistas fueron acosados continuamente, sufriendo las arbitrariedades de los dirigentes y la continua presencia policial en la sede. ${ }^{55}$

Entendemos que la acometida contra los gremios peronistas y la promoción del sindicalismo libre dio lugar a un proceso de descentralización de las fuerzas sindicales. En definitiva, las disputas por la representación de las demandas de la fuerza laboral en la provincia de Jujuy formaron parte del proceso de la reestructuración del orden sindical peronista.

En Jujuy, el proceso de intervención en la esfera gremial se mantuvo firme durante los primeros meses de 1956, en cuanto la conversión de los sindicatos en entidades "libres" y el destierro de los dirigentes peronistas se llevaban a cabo paulatinamente con éxito. No obstante, los militantes peronistas no fueron derrotados con facilidad; en los gremios de la provincia subsistieron largamente las luchas contra el régimen "revolucionario". De acuerdo a una comisión extraordinaria enviada por el gobierno central a reseñar el estado de la desperonización de los gremios, en la provincia de Jujuy había problemas "derivados por la acción de determinados dirigentes agitadores que aún continúan pretendiendo engañar a la masa obrera para mantener sus posiciones de privilegio". ${ }^{66}$ Sin embargo, en términos generales y a mediano plazo, la preponderancia de los peronistas terminó cayendo bajo el peso de las políticas del gobierno.

La disminución de la gravitación del peronismo se hizo evidente a lo largo de 1956 y principios de 1957. Los cambios en las orientaciones repercutieron en las relaciones entre la fuerza de trabajo y los dueños de los medios de producción. En el caso de los ingenios, la falta de oposición en los gremios favoreció la rebaja en los salarios. Así, los controladores de básculas, que percibían 950 pesos en moneda nacional al cierre de la zafra de 1955, para 1957 el salario se redujo a 650.57 En los trabajos de recolección de caña de azúcar, "se ha utilizado un trato descomedido con los obreros, a quienes se los amenazó constantemente, invocándoles el cambio político que hubo en el país". ${ }^{58}$ También se evidenció que los trabajadores de las plantaciones cítricas en Calilegua no habían recibido el aumento salarial que por ley les correspondía, y que a los jornaleros radicados en el departamento de Santa Clara hacía meses que no le liquidaban los

\footnotetext{
51 AHJ. Expediente $N^{\circ}$ 90-A-1955.

52 AHJ. Expediente $\mathrm{N}^{\circ} 28-\mathrm{U}-1955$.

53 HBPJ. Libertad. 8 de diciembre de 1955.

54 Expediente $\mathrm{N}^{\circ} 106-\mathrm{L}-1956$.

55 La vigilancia en las empresas fue un dato recurrente en este período. Por ejemplo, en el caso de la Primera Hilandería y Tejeduría Jujeña, a través de la infiltración de infidentes, se había construido un detallado archivo de las actividades de los trabajadores. AHJ. Expediente $\mathrm{N}^{\circ} 421-\mathrm{P}-1958$.

56 HBPJ. Libertad. 24 de febrero de 1956.

57 AHJ. Expediente $\mathrm{N}^{\circ}$ 949-S-1957.

58 HBPJ. Pregón. 16 de octubre de 1956.
} 
sueldos. ${ }^{59} \mathrm{Asimismo}$, en la esfera gastronómica no se respetaron los convenios. ${ }^{60}$

Fueron numerosas las denuncias que se llevaron a cabo en torno a los incumplimientos de las leyes laborales; la mayoría de estas inculpaciones a las empresas provinieron de parte de los partidos políticos (ciertamente con simpatías manifiestas por seducir a la fuerza de trabajo).

La depuración de los sindicatos jujeños se hizo evidente sobre todo a través del reforzamiento de una identidad y un discurso estrictamente gremial, es decir, vaciado de política. Sin dudas, los sindicatos no dejaron de interpelar a las autoridades requiriendo la solución de los problemas de sus afiliados. Sin embargo, estas demandas estaban teñidas de peticiones puntuales, que rara vez excedían los marcos impuestos por las empresas en las que se desenvolvían. Los organismos obreros no realizaron denuncias respecto de las inobservancias de la legislación laboral. Por otro lado, se hizo evidente también durante este período la inexistencia de una central obrera, dado que la CGT, intervenida por el gobierno, estaba orientada antes a eliminar los residuos "totalitarios" que a organizar al movimiento obrero. Esta carencia se evidenció en cuanto los pedidos gremiales (puntuales, como se mencionó) no iban más allá de los intereses estrictos de cada uno de los sindicatos.

En general estas demandas eran presentadas en forma de petitorio y hacían referencia en algunos casos a las condiciones de vida de los trabajadores, pero siempre sin presentar amenaza tanto para las autoridades provinciales como para la patronal. Por ejemplo, los obreros del Lote Barro Negro, afiliados al Sindicato de obreros y empleados del Ingenio Río Grande, se dirigieron a la Intervención Federal informándoles que algunas de las viviendas del Lote se encontraban en malas condiciones; "pedimos que se nos mejoren y también pedimos un carro regador para el pueblo y control de la carne y precios en la carniceria de esta localidad". ${ }^{61}$ En otro caso, el Sindicato de Obreros y Empleados del Ingenio Río Grande planteó al régimen intervencionista los problemas de la localidad, y sugirieron que se realizaran mejoras en las viviendas y se instalase una escuela. ${ }^{62}$ Durante este período, la única demanda de mejora salarial fue solicitada por el Sindicato de Obreros y Empleados del Azúcar del Ingenio La Esperanza, en vista de que se habría de discutir próximamente un nuevo convenio colectivo de trabajo. ${ }^{63}$

\section{El regreso del peronismo a la lucha sindical}

A lo largo de 1956, en Jujuy, un sector de los sindicalistas peronistas se mantuvo en la lucha por la recuperación de los gremios. Sin embargo, otro grupo optó por la militancia en los comandos de la resistencia. Desde los albores de 1957 se comenzó a hacer evidente el renacimiento de los activistas gremiales peronistas; esta tendencia radicó en la confluencia de tres procesos: por un lado, la persistencia de un remanente de militantes peronistas que sobrevivió a las purgas estatales logró mantener activa la lucha en los sindicatos; por otro, el retorno de los miembros de los comandos a la lucha sindical, que le insufló nuevos bríos al bando

59 HBPJ. Pregón. 16 de octubre de 1956.

60 AGN. Fondo: Ministerio del Interior - Expedientes Secretos, Confidenciales y Reservados. Caja: $136 . \mathrm{N}^{\circ}$ de documento: 23. El Radical. $\mathrm{N}^{\circ} 3.11$ de marzo de 1957.

61 AHJ. Expediente $N^{\circ} 1279-\mathrm{S}-1956$.

62 AHJ. Expediente $N^{\circ} 1281-\mathrm{S}-1956$.

63 AHJ. Expediente $\mathrm{N}^{\circ} 1555-\mathrm{P}-1956$. 
gremial peronista; finalmente, (como ya se señaló) en una serie de procedimientos orientados a la normalización del movimiento obrero a principios de 1957. Señala James que la mayor parte de los dirigentes sindicales que participaron en la organización del movimiento obrero eran "figuras nuevas, surgidas en el curso de las luchas suscitadas en las fábricas y talleres desde la caída de Perón". ${ }^{64} \mathrm{~A}$ nuestro criterio, el retorno de los sindicalistas que habían participado en los comandos supuso un proceso inverso, en el sentido de que varios de éstos pertenecían a la dirigencia sindical previa al golpe de septiembre de 1955. Puede incluso suponerse que en algunos gremios se llevó a cabo el re-anquilosamiento de las estructuras de los mismos, como procedimiento inverso al que señala el autor. ${ }^{65}$

Poco a poco, los peronistas fueron recuperando lugar en los sindicatos e imponiendo una nueva tonalidad a las prácticas gremiales. Este cambio paulatino se hizo evidente primero a través de acciones colectivas basadas en prácticas de interpelaciónque los gremios instalaron en el espacio público. A diferencia de lo acaecido durante 1956, el siguiente año trajo consigo múltiples demandas salariales y, como dato sumamente novedoso, huelgas, ampliando el repertorio de las acciones de protesta. Mientras durante la primera mitad de 1957 los gremios fueron mayormente reorganizándose, a lo largo del segundo semestre, con el triunfo peronista a través del voto en blanco, los trabajadores se lanzaron con ímpetu a las luchas salariales. ${ }^{66}$

La Unión de Sindicatos de Trabajadores Municipales de la República Argentina, en este nuevo contexto, puso de manifiesto la posición de los asalariados, que había sido escamoteada durante el año precedente:

Ninguna obra, ni la vida institucional del país, se puede consolidar sobre las necesidades de los más humildes, que por lo mismo, carecen de la defensa dentro del concierto social imprescindible para hacer frente a contingencias desfavorables como las que estamos pasando todos los habitantes de este país. ${ }^{67}$

Los obreros de la Municipalidad de San Salvador de Jujuy también postularon principios similares:

No es imposible hacer frente a los gastos de la vida contando con una paga tan exigua como la que tenemos. Por ello venimos a solicitar de V. E. disponga el aumento de nuestros haberes que permita la sobrevivencia de nosotros y de nuestras familias, gentes humildes que somos, que vivimos en el más grande estado de estrechez. ${ }^{68}$

Los empleados del municipio capitalino reclamaron el aumento de los jornales. En septiembre de 1957, los jornales variaban entre 28 y 30 pesos. La demanda comportaba el aumento de acuerdo al grupo familiar: padre, madre y cuatro niños, \$49,90 m/n; padre, madre y cinco hijos, $\$ 58 \mathrm{~m} / \mathrm{n}$; padre, Madre y nueve hijos, entre varones y mujeres, que van a la escuela, $\$ 61,30 \mathrm{~m} / \mathrm{n}$.

64 JAMES. Resistencia e Integración, p. 107.

65 JAMES, Daniel. "Power and politics in the peronist trade unions". Journal of Interamerican Studies and world affairs, vol. 20, $\mathrm{n}^{\circ} 1$, p. 3-36 (1978).

66 En julio de 1957 se llevaron a cabo elecciones de convencionales constituyentes, alentadas por (entre otros motivos) por medir los caudales de votos de las fuerzas políticas. El peronismo, proscripto y sin representación formal, optó por el voto en blanco. El mismo se impuso de manera general en todo el país, incluyendo la provincia de Jujuy.

67 AHJ. Expediente $\mathrm{N}^{\circ} 37-\mathrm{U}-1957$.

68 AHJ. Expediente $\mathrm{N}^{\circ} 459-\mathrm{V}-1957$. 
Los trabajadores comenzaron a denunciar a las empresas por el incumplimiento de las normas laborales. Por ejemplo, el Sindicato de Luz y Fuerza de Jujuy manifestó la falta de pago de los Convenios de Trabajo de los años 1954 y 1956 por parte de la Empresa Privada de energía eléctrica de Libertador General San Martín, lo cual "hace insostenible la situación de los hogares obreros afectados por la creciente carestía de vida". ${ }^{69}$ La Unión de Trabajadores Gastronómicos de la República Argentina denunció a los bares de la ciudad capital por no pagar el aumento de 18 por ciento "estipulado en un convenio anterior" y el aguinaldo, y por no conceder vacaciones a sus empleados. ${ }^{70}$

Los obreros de la construcción declararon, finalmente, una huelga de 48 horas en octubre de 1957 reclamando en contra de la patronal, que se negaba a otorgar "un aumento de emergencia de \$30 por jornal”. ${ }^{71}$ También pararon los empleados de la construcción en la localidad de Volcán. Los mismos estaban construyendo el barrio ferroviario; empleados por la empresa Deck, demandaban que esta "les pague las tres quincenas que adeuda y que se abonen la retroactividad y el aguinaldo". ${ }^{2}$ También realizaron una huelga los telefónicos, interrumpiendo el servicio. Generalmente las huelgas de los telefónicos no involucraban al personal de tráfico; no obstante, éstos se solidarizaron y participaron también del paro. La medida de fuerza, como era de esperarse, fue declarada ilegal por la Intervención Federal. ${ }^{73}$

Finalmente, el proceso abierto a principios de 1957 comportó el inicio de la reconstitución de la CGT, cuyos gremios lograronliberarse parcialmente de la influencia de las intervenciones enviadas por el gobierno. Ciertamente, el proceso de normalización había arrancado en los albores de ese año con acontecimientos como las elecciones en el Sindicato Libre de Taximetristas de Libertador General San Martín. ${ }^{74}$ Sin embargo, el proceso fue coartado por el gobierno. No obstante, el control de los gremios fue paulatinamente recuperado por los dirigentes peronistas; por ejemplo, en los gremios de los trabajadores azucareros lograron expulsar a los representantes de los ingenios.

La central obrera, que se encontraba reconformándose, sufrió la clausura de su local. Como respuesta,

\footnotetext{
Se constituyó una CGT Provisoria ( ) encabezada por Máximo Tell y una Comisión Intersindical Jujeña, que no sólo resistió "las condiciones antiobreristas" impuestas sino que tuvo que soportar la persecución del líder ( ) [y afrontar] la oposición en el interior de la organización.75
}

La oposición a la CGT Provisoria provino fundamentalmente de parte de los sindicatos azucareros, acompañados por los telegrafistas. La discusión entre ambos bandos radicó en que los azucareros eran más proclives a aceptar las limitaciones interpuestas por el gobierno para la devolución del local. En definitiva, los telegrafistas y los azucareros sostenían que la CGT debía recibirse sin imponerle condiciones a la Intervención Federal. Esto es, lo que privilegiaban los

69 AHJ. Expediente $N^{\circ}$ 537-D-1957.

70 AHJ. Expediente $\mathrm{N}^{\circ} 11-\mathrm{U}-1957$.

71 AHJ. Expediente $\mathrm{N}^{\circ} 47-\mathrm{U}-1957$.

72 AHJ. Expediente $\mathrm{N}^{\circ} 47-\mathrm{U}-1957$.

73 HBPJ. Pregón. 17 de septiembre de 1957.

74 HBPJ. Pregón. 30 de enero de 1957.

75 FLEITAS; KINDGARD. “Entre la legalidad y la proscripción”, p. 221. 
azucareros era el reconocimiento estatal de la CGT. ${ }^{76}$ Esta postura les costó que los cegetistas provisorios los tildaran de "estar entregados al gobierno". ${ }^{77}$ Ante la huelga declarada por la CGT Provisoria se establecieron tres posturas: por un lado, los gremios alineados con la central; por otra parte los que apoyaban a la CGT Provisoria pero que no pararon y, por último, los que la repudiaron.

Las diferencias entre los diversos sectores sindicales no fueron resueltas a corto plazo. Incluso, casi a punto de expirar el mandato de la Intervención Federal, el local de la CGT no había sido devuelto a los gremios. A principios de 1958, con la situación de la reconstitución de la CGT todavía sin resolver, los sindicatos se sumaron a las discusiones en torno a qué camino debería seguir el peronismo de cara a las elecciones del mismo año. No obstante, más allá de las internas en el seno del sindicalismo, cabe resaltar que la impronta del peronismo gravitaba por completo en los gremios.

\section{Consideraciones finales}

La política fomentada por la Revolución Libertadora en la provincia de Jujuy (tanto en lo que concierne a la dinámica organizacional de la clase obrera como a sus mecanismos represivos) desencadenó un reajuste en el interior del movimiento obrero e impactó contra el conjunto de los asalariados. No obstante, más allá de tales medidas y sus consecuencias en el mundo de los trabajadores, el movimiento obrero jujeño desarrolló a lo largo del período una fuerte oposición a la gestión. La resistencia peronista se constituyó en un bastión contra la tutela militar, asumiendo una postura enérgica contra el mismo en el campo de los trabajadores. Tal posición supuso líneas de acción generales, cuyas trayectorias llevaron a la rama sindical del peronismo de la proscripción al dominio de la central obrera de la provincia. Los itinerarios recorridos por los gremialistas peronistas jujeños fueron diferentes a los observados por los autores en otras áreas geográficos. La salida de militantes de los sindicatos a los comandos y a la inversa y la falta recambio generacional son ejemplos de prácticas específicas del espacio peronista local.

La resistencia se desarrolló ciertamente bajo diversas modalidades y niveles de organización, producto de las condiciones impuestas por las estrategias gubernamentales y asimismo por la dinámica interna del colectivo de trabajadores. La disidencia ejercida contra el régimen se llevó a cabo con aparentes intermitencias, en cuanto el flujo mencionado vaciaba y limitaba la capacidad de acción de los comandos y de la lucha sindical. La lógica política provincial estableció así que la lucha en el frente sindical se retrotrajese luego del golpe y se retomase a partir de principios de 1957. No obstante, más allá de las limitaciones, el sector sindical no claudicó, en cuanto persistió en las luchas obreras. Lo cierto, en definitiva, es que el sindicalismo peronista jujeño luchó por recuperar el control de los gremios y la CGT.

Al final del proceso, era evidente por un lado que el régimen no había podido coartar al sindicalismo y por otro, que los peronistas no sólo habían logrado sobrevivir sino también que se habían hecho dueños de la central obrera. Las disputas internas en la CGT excluían a sectores que no estaban vinculados al peronismo. En fin, se hizo ostensible que el proceso de desperonización no

76 HBPJ. Pregón. 24 de septiembre de 1957.

77 HBPJ. Pregón. 15 de octubre de 1957. 
había funcionado en ninguno de sus niveles posibles; ni se había expulsado a los peronistas de la estructura sindical ni se había erradicado la identidad peronista.

Recebido em 20/06/2015 Aprovado em 16/11/2015 
